Article

\title{
Phytochemical Properties and Anti-Proliferative Activity of Olea europaea L. Leaf Extracts against Pancreatic Cancer Cells
}

\section{Chloe D. Goldsmith ${ }^{1, *}$, Quan V. Vuong ${ }^{1}$, Elham Sadeqzadeh ${ }^{2}$, Costas E. Stathopoulos ${ }^{3}$,} Paul D. Roach ${ }^{1}$ and Christopher J. Scarlett ${ }^{1}$

1 Nutrition Food \& Health Research Group, School of Environmental and Life Sciences, University of Newcastle, Ourimbah, NSW 2258, Australia;

E-Mails: vanquan.vuong@newcastle.edu.au (Q.V.V.); paul.roach@newcastle.edu.au (P.D.R.); c.scarlett@newcastle.edu.au (C.J.S.)

2 School of Biomedical Sciences and Pharmacy, University of Newcastle, Ourimbah, NSW 2258, Australia; E-Mail: elham.sadeqzadeh@newcastle.edu.au

3 Faculty of Bioscience Engineering, Ghent University Global Campus, Incheon 406-840, Korea; E-Mail: costas.stathopoulos@ghent.ac.kr

* Author to whom correspondence should be addressed; E-Mail: chloe.d.goldsmith@uon.edu.au; Tel.: +61-2-4349-4568.

Academic Editor: Marcello Iriti

Received: 29 May 2015 / Accepted: 14 July 2015 / Published: 17 July 2015

\begin{abstract}
Olea europaea L. leaves are an agricultural waste product with a high concentration of phenolic compounds; especially oleuropein. Oleuropein has been shown to exhibit anti-proliferative activity against a number of cancer types. However, they have not been tested against pancreatic cancer, the fifth leading cause of cancer related death in Western countries. Therefore, water, 50\% ethanol and 50\% methanol extracts of Corregiola and Frantoio variety Olea europaea L. leaves were investigated for their total phenolic compounds, total flavonoids and oleuropein content, antioxidant capacity and anti-proliferative activity against MiaPaCa-2 pancreatic cancer cells. The extracts only had slight differences in their phytochemical properties, and at 100 and $200 \mu \mathrm{g} / \mathrm{mL}$, all decreased the viability of the pancreatic cancer cells relative to controls. At $50 \mu \mathrm{g} / \mathrm{mL}$, the water extract from the Corregiola leaves exhibited the highest anti-proliferative activity with the effect possibly due to early eluting HPLC peaks. For this reason, olive leaf extracts warrant further investigation into their potential anti-pancreatic cancer benefits.
\end{abstract}


Keywords: olive leaf; oleuropein; pancreatic cancer; phenolic compounds; Olea europaea L.; antioxidant activity; phytochemicals; biophenols

\section{Introduction}

Olea europaea L. leaf (olive leaf) is a waste product of the olive oil extraction process, weighing up to $10 \%$ of the material arriving at the mill. Currently, this by-product is not profitable; olive leaves are often used as animal feed or simply burned with excess branches gathered from pruning [1,2]. Many olive oil producers even charge a fee to the olive farmer for the disposal of olive leaves. The interest in olive leaf has grown in recent years due to the high concentration of phenolic compounds, of which oleuropein is the most abundant. A number of the health benefits of virgin olive oil consumption have been attributed to oleuropein. It has been found to have anti-atherogenic [3], anti-inflammatory [4] and antimicrobial [5] properties. More recently, oleuropein has been investigated for its potent anti-cancer activity. It has been shown to inhibit proliferation and migration of a number of advanced grade human tumour cell lines in a dose dependent manner [6-11]. However, the effect of olive phenolic compounds has yet to be investigated for pancreatic cancer.

Pancreatic cancer is a devastating heterogeneous disease with significant resistance to the limited conventional treatment options and the current chemotherapy agents are highly toxic [12,13-15]. Thus, it is essential to control and manage the development of pancreatic cancer [16] as well as to develop novel therapeutic strategies against it. The use of olive phenolic compounds may serve as a useful strategy to inhibit carcinogenesis [14]. To our knowledge there has not been any investigation into the effect of olive leaf phenolic compounds on pancreatic cancer cells.

It is important to understand the effect different extraction conditions have on phenolic compound yield. A number of methods have been proposed for the extraction of phenolic compounds from olive leaves [17-19]. However, it is difficult to compare these studies since they use very different methods including advanced technologies and an array of different solvents. Furthermore, the use of advanced technologies, including microwave and ultrasound-assisted extraction methods, are difficult to scale up to an industrial setting and organic solvents can be expensive and difficult to dispose of. This has led to a push from industry and researchers for the development of more environmentally friendly, or "green" extraction techniques, for example, using water as an extraction solvent. However, it is important to understand the efficacy of these "green" extraction protocols compared to organic solvent extraction methods and advanced technologies.

We hypothesised that water is an effective extraction solvent for preparing oleuropein rich olive leaf extracts with anti-pancreatic cancer activity. Therefore, this study aimed to characterise the phytochemical properties of olive leaf extracts obtained from two different cultivars of olive leaves via different previously optimised extraction methods. A water extraction method was compared to two ultrasound-assisted extraction methods with $50 \%$ ethanol or $50 \%$ methanol as the solvent. The anti-pancreatic cancer effect of these extracts was also assessed. 


\section{Results and Discussion}

There were no differences between the Corriola and Frantoio varieties in their TPC, total flavonoids and oleuropein content (Table 1) and in their antioxidant capacity (Table 2). Many variables can affect the phenolic compound content of olive products including the position on the tree, cultivar, soil mineral content as well as sun exposure. However, the geographic location of the tree has been shown to have the largest effect on the phenolic compound profile of olive products [20]. Therefore, it is likely that the reason that no difference was seen between the two different varieties of olive leaves was that they were from the same location.

Table 1. Phytochemical properties of olive leaf extracts. Total phenolic compounds (TPC) are expressed as gallic acid equivalents (GAE)/g of extract, total flavonoids are expressed as rutin equivalents $(\mathrm{RE}) / \mathrm{g}$ of extract and oleuropein is expressed as $\mathrm{mmol} / \mathrm{g}$ of dried extract.

\begin{tabular}{|c|c|c|c|c|}
\hline Solvent & Cultivar & $\begin{array}{c}\text { TPC } \\
(m g \text { GAE } / g)\end{array}$ & $\begin{array}{l}\text { Total Flavonoids } \\
\text { (mg RE/g) }\end{array}$ & $\begin{array}{c}\text { Oleuropein } \\
(\mu \mathrm{mol} / \mathrm{g})\end{array}$ \\
\hline Water & Corregiola & $230.15 \pm 6.85^{\mathrm{a}}$ & $345.45 \pm 85.71^{\mathrm{a}}$ & $86.33 \pm 1.41^{a}$ \\
\hline Ethanol $(50 \%)$ & Corregiola & $238.70 \pm 11.85^{\mathrm{a}}$ & $828.13 \pm 47.82^{b}$ & $114.54 \pm 1.14^{b}$ \\
\hline Methanol (50\%) & Corregiola & $231.05 \pm 11.15^{\mathrm{a}}$ & $539.53 \pm 18.16^{\mathrm{a}}$ & $109.54 \pm 3.92^{b}$ \\
\hline Water & Frantoio & $233.45 \pm 0.20^{\mathrm{a}}$ & $442.95 \pm 16.52^{\mathrm{a}}$ & $85.11 \pm 1.65^{\mathrm{a}}$ \\
\hline Ethanol (50\%) & Frantoio & $241.60 \pm 23.5^{\mathrm{a}}$ & $1035.79 \pm 121.25^{b}$ & $111.93 \pm 5.80^{b}$ \\
\hline Methanol (50\%) & Frantoio & $236.20 \pm 11.02^{\mathrm{a}}$ & $528.51 \pm 43.87^{\mathrm{a}}$ & $105.01 \pm 1.13^{b}$ \\
\hline
\end{tabular}

a,b Values in the same column not having the same superscript letter are significantly different from each other $(p<0.05)$.

Table 2. Antioxidant capacity of olive leaf extracts measured using three different antioxidant activity assays. DPPH is expressed as \% inhibition and FRAP and CUPRAC are expressed as $\mathrm{mg}$ trolox equivalents (TRE)/g of dried extract.

\begin{tabular}{|c|c|c|c|c|}
\hline Solvent & Cultivar & $\begin{array}{c}\text { DPPH } \\
\text { (\% Inhibition) }\end{array}$ & $\begin{array}{c}\text { FRAP } \\
\text { (mg TRE/g) }\end{array}$ & $\begin{array}{c}\text { CUPRAC } \\
(\mathrm{mg} \text { TRE/g) }\end{array}$ \\
\hline Water & Corr & $74.75 \pm 5.85^{\mathrm{a}}$ & $22.85 \pm 19.17^{\mathrm{a}}$ & $308.65 \pm 36.83^{a}$ \\
\hline Ethanol (50 & Corregiola & $70.97 \pm$ & $218.51 \pm 49.34^{\mathrm{a}}$ & $322.32 \pm 32.99^{a}$ \\
\hline Methanol (50\%) & Corregiola & $84.25 \pm 4.31^{\mathrm{a}}$ & $237.81 \pm 35.49^{\mathrm{a}}$ & $302.54 \pm 6.75^{a}$ \\
\hline Water & Frantoio & $75.61 \pm 2.73^{\mathrm{a}}$ & $232.12 \pm 4.89^{a}$ & $318.07 \pm 59.76^{a}$ \\
\hline Ethanol (50\%) & Frantoio & $86.34 \pm 4.27^{\mathrm{a}}$ & $303.44 \pm 19.81^{\mathrm{a}}$ & $326.62 \pm 21.71^{a}$ \\
\hline Methanol (50\%) & Frantoio & $86.63 \pm 8.19^{\mathrm{a}}$ & $216.15 \pm 55.66^{a}$ & $303.92 \pm 22.17^{a}$ \\
\hline
\end{tabular}

${ }^{a}$ All values in the same column were not significantly different from each other $(p>0.05)$.

\subsection{The Influence of Extraction Methods on Phytochemical Properties}

The different solvents and extraction conditions had no effect on the TPC but did influence the total flavonoids and the oleuropein content in the extracts (Table 1). The water extract had a lower level of total flavonoids and oleuropein while the methanol extract had a lower level of total flavonoids, when compared to the ethanol extract. Flavonoids are the largest group of phenolic compounds and include both polar and non-polar moieties. The $50 \%$ ethanol extract contained more than double the total 
flavonoids compared to the water extract (Table 1). This suggests that the majority of the compounds present in the olive leaves were either less polar flavonoids or were potentially heat sensitive compounds which were degraded during the water extraction process conducted at $90{ }^{\circ} \mathrm{C}$ for $70 \mathrm{~min}$ [21]. Consistent with this, acetone is well known to be the best solvent for the extraction of flavonoids [21] and acetone is less polar than $50 \%$ ethanol.

The typical HPLC chromatograms for the different extraction protocols (Figure 1) showed similar peak profiles. However, the earlier-eluting less polar peaks (1-7) were slightly larger in the water extract while the later-eluting more polar peaks (9-17) were larger in the ethanol and methanol extracts. The greatest effect was seen in peak 12, for which the area was more than tripled in the ethanol and methanol extracts compared to the water extract.

Since oleuropein (peak 13) is one of the less polar compounds in the HPLC chromatograms (Figure 1), it was not surprising to see that the organic solvents extracted more of it from the olive leaves. However, the water method still extracted approximately $80 \%$ of the oleuropein compared to the ethanol extraction method. Moreover, there was no difference in the level of TPC between the different extracts. Therefore, when considering the current push towards "green" extraction protocols, the water extraction method [21] is an excellent candidate for industrialisation.

\subsection{The Influence of Extraction Methods on Antioxidant Capacity}

Despite the differences in the phytochemical properties of the extracts obtained with the different solvents, there was no significant difference in their antioxidant capacity as measured via the DPPH, FRAP or CUPRAC assays (Table 2). This was not surprising since although individual compounds did vary depending on the extraction conditions, there was no difference in the TPC of the different extracts (Table 1). This further highlights the effectiveness of this "green" water extraction protocol. Additionally, previous reports have shown that antioxidant activity can increase in extracts whose high molecular weight compounds have degraded into more active lower molecular weight compounds. One example of this is the degradation of oleuropein into hydroxytyrosol and tyrosol. However, this seems unlikely since tyrosol (peak 5) was not detected in significant amounts and hydroxytyrosol was not detected at all in the HPLC chromatograms (Figure 1).

\subsection{The Influence of Extraction Methods on Growth Inhibition of Pancreatic Cancer Cells in Vitro}

At a concentration of $200 \mu \mathrm{g} / \mathrm{mL}$, all of the crude olive leaf extracts for both the Corregiola and Frantoio cultivars were able to reduce the viability of the MiaPaCa- 2 cells to less than $1 \%$ relative to controls, and they were significantly more toxic (47.8\%) than the chemotherapy drug gemcitabine at its $\mathrm{IC}_{50}$ of $50 \mathrm{~nm}$ (Table 3). At $100 \mu \mathrm{g} / \mathrm{mL}$, the water extract of the Frantoio variety $(0.47 \%)$, the $50 \%$ ethanol extract of the Corregiola variety $(4.26 \%)$ and the water extract of the Corregiola variety (14.59\%) demonstrated a significantly greater effect on the cell viability of the MiaPaCa-2 cells compared to the $50 \%$ ethanol $(30.37 \%)$ and the $50 \%$ methanol $(41.13 \%)$ extracts of the Frantoio variety and the $50 \%$ methanol extract of the Corregiola variety (32.83\%). However, all the extracts at $100 \mu \mathrm{g} / \mathrm{mL}$ were still more toxic than gemcitabine at its $\mathrm{IC}_{50}$ (Table 3). 

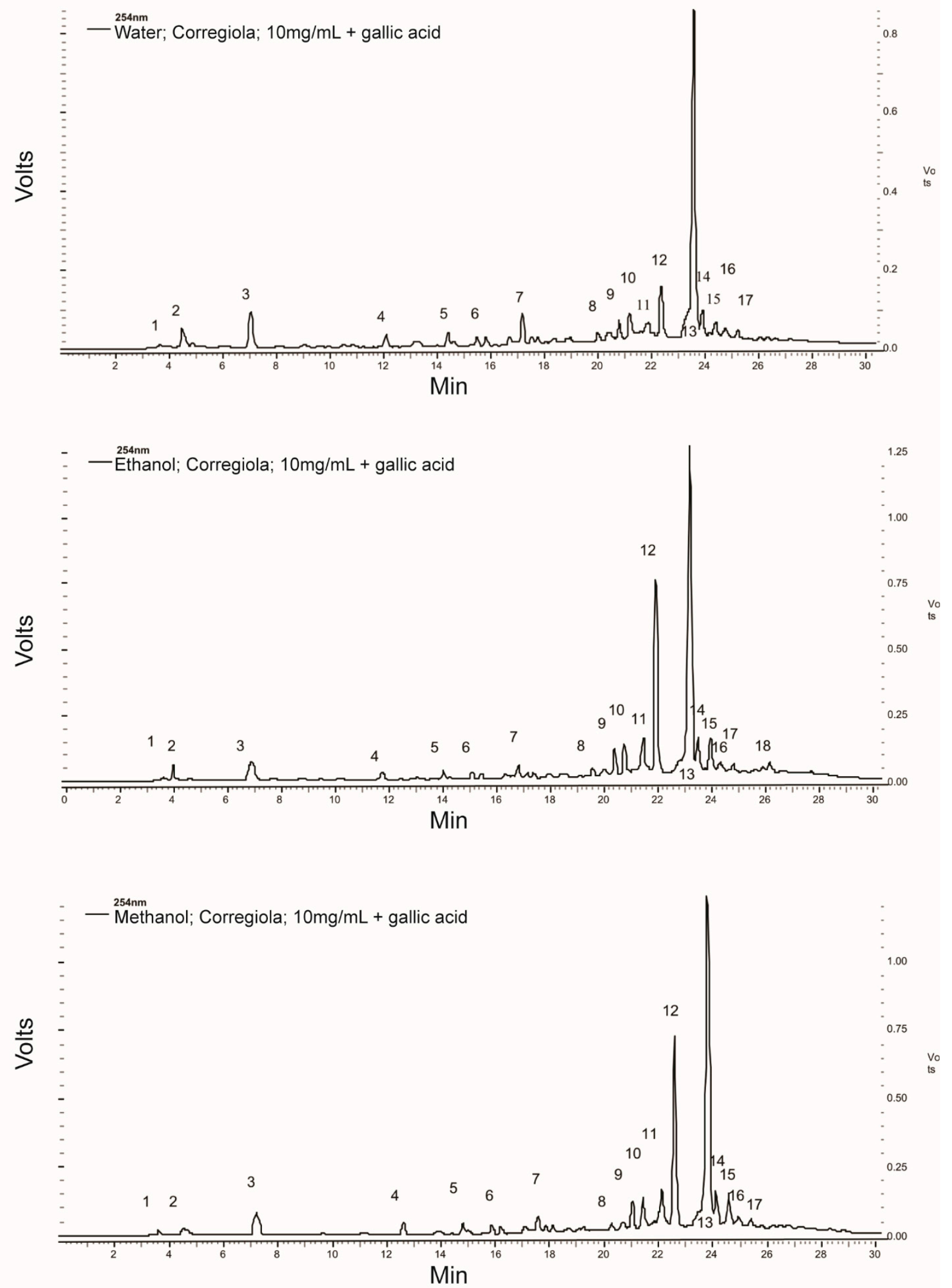

Figure 1. Typical HPLC chromatograms for the water, 50\% ethanol and 50\% methanol extracts from olive leaves. Peaks identified were: (3) gallic acid (internal standard), (5) tyrosol and (13) oleuropein. 
Table 3. Anti-proliferative activity of olive leaf extracts $(0-200 \mu \mathrm{g} / \mathrm{mL})$ on MiaPaCa-2 pancreatic cancer cells. Results are expressed as \% viability compared to controls \pm standard deviation.

\begin{tabular}{ccccccc}
\hline \multirow{2}{*}{ Solvent } & \multirow{2}{*}{ Cultivar } & \multirow{2}{*}{$\begin{array}{c}\text { Gemcitabine } \\
\mathbf{( 5 0} \mathbf{~ n M})\end{array}$} & \multicolumn{4}{c}{ Concentration of Olive Leaf Extract $(\boldsymbol{\mu g} / \mathbf{m L})$} \\
\cline { 4 - 6 } & & $\mathbf{0}($ Controls) & $\mathbf{5 0}$ & $\mathbf{1 0 0}$ & $\mathbf{2 0 0}$ \\
\hline water & Corregiola & & $100^{\mathrm{a}, \mathrm{i}}$ & $55.89 \pm 3.53^{\mathrm{b}, \mathrm{i}}$ & $14.59 \pm 0.5^{\mathrm{c}, \mathrm{i}}$ & $0.63 \pm 0.29^{\mathrm{c}, \mathrm{i}}$ \\
ethanol & Corregiola & & $100^{\mathrm{a}, \mathrm{i}}$ & $121.59 \pm 13.7^{\mathrm{a}, \mathrm{ii}}$ & $4.26 \pm 2.6^{\mathrm{b}, \mathrm{ii}}$ & $0.44 \pm 2.08^{\mathrm{b}, \mathrm{i}}$ \\
methanol & Corregiola & $100^{\mathrm{a}, \mathrm{i}}$ & $73.57 \pm 9.33^{\mathrm{b}, \mathrm{ii}}$ & $32.83 \pm 10.41^{\mathrm{c}, \mathrm{iii}}$ & $0.87 \pm 0.17^{\mathrm{d}, \mathrm{i}}$ \\
water & Frantoio & $100^{\mathrm{a}, \mathrm{i}}$ & $103.19 \pm 27.9^{\mathrm{a}, \mathrm{ii}}$ & $0.47 \pm 0.13^{\mathrm{b}, \mathrm{ii}}$ & $0.61 \pm 0.17^{\mathrm{b}, \mathrm{i}}$ \\
ethanol & Frantoio & $100^{\mathrm{a}, \mathrm{i}}$ & $122.78 \pm 21.1^{\mathrm{a}, \mathrm{ii}}$ & $30.37 \pm 4.48^{\mathrm{b}, \mathrm{iii}}$ & $0.87 \pm 0.22^{\mathrm{c}, \mathrm{i}}$ \\
methanol & Frantoio & & $100^{\mathrm{a}, \mathrm{i}}$ & $120.26 \pm 9.22^{\mathrm{b}, \mathrm{ii}}$ & $41.13 \pm 16.02^{\mathrm{c}, \mathrm{iii}}$ & $0.98 \pm 0.56^{\mathrm{c}, \mathrm{i}}$ \\
& control & & $100^{\mathrm{a}, \mathrm{i}}$ & & & \\
\hline
\end{tabular}

a,b,c,d Values in the same row not having the same superscript letter are significantly different from each other. i,ii,iii Values in the same column not having the same superscript roman numeral are significantly different from each other. Values are expressed as percentage growth compared to controls with no extracts or gemcitabine. Therefore, the lower the value in response to olive leaf extract $(50-200 \mu \mathrm{g} / \mathrm{mL})$, the greater the anti-proliferative effect. Values greater than $100 \%$ represent cell growth greater than controls. Time $=96 \mathrm{~h}$.

Interestingly, at $50 \mu \mathrm{g} / \mathrm{mL}$, the water extract of the Corregiola variety (55.89\%) had a significantly greater negative impact on the MiaPaCa-2 cells' viability than all the other extracts (Table 3). The compounds eluting as peaks 2 and 3 in the HPLC chromatogram (Figure 1) for the Corregiola variety are of interest because they appear more prominent in the water extract than in the other two extracts. However, the water extract from the Corregiola olive tree leaves may also have other compounds which are not detected at $254 \mathrm{~nm}$.

Figure 1 shows the phenolic compound profile of the olive leaf samples and it appears that oleuropein (peak 13) is by far the most abundant compound present. However, at a concentration of $200 \mu \mathrm{g} / \mathrm{mL}$, the crude olive leaf extracts only contained approximately $20 \mathrm{nM}$ of oleuropein. Despite this very low dose, the crude leaf extracts were still able to significantly reduce the viability of the pancreatic cancer cells compared to gemcitabine at its $\mathrm{IC}_{50}(p<0.05)$. The anti-proliferative capacity of the olive leaf extracts in the present study against pancreatic cancer cells is better than what has been observed in previous studies on cancers of different origins. Han et al. [22] showed that $200 \mu \mathrm{g} / \mathrm{mL}$ of pure oleuropein was able to dramatically reduce the cell viability of MCF-7 human breast cancer cells. Further investigation discovered that oleuropein decreased the number of MCF-7 cells by inhibiting the rate of proliferation and inducing cell apoptosis. However, the results suggest that the water extract from the Corregiola leaves may have other active compounds, which are more potent against this pancreatic cell line than oleuropein, since the water extracts from both olive varieties were significantly lower, not higher, in oleuropein than the 50\% ethanol and 50\% methanol extracts (Table 1). Therefore, the present study provides a platform for further research into olive leaf phenolic compounds and their efficacy. 


\section{Experimental Section}

\subsection{Materials}

Folin Ciocalteu's reagent, sodium carbonate, gallic acid, Sodium Nitrite, aluminium chloride, sodium hydroxide, rutin, 1,1-diphenyl-2-picrylhydrazyl (DPPH), 6-hydroxy-2,5,7,8-tetramethylchroman2-carboxylic acid (trolox), 2,4,6-Tris(2-pyridyl)-s-triazine (TPTZ), ferric chloride, sodium acetate, acetic acid, copper(II) chloride, ammonium acetate $\left(\mathrm{NH}_{4} \mathrm{Ac}\right)$, neocuproine methanol and ethanol were purchased from Sigma Aldrich (Castle Hill, NSW, Australia).

Human pancreatic cancer (Mia-PaCa2) cells, Dulbecco's Modified Eagle's Medium (DMEM), fetal bovine serum (FBS), horse serum and L-glutamine.

\subsection{Sample Preparation and Extraction of Phenolic Compounds}

Corregiola and Frantoio olive leaves were obtained from Houndsfield Estate in the Hunter Valley of NSW Australia. Leaves were dried at $120^{\circ} \mathrm{C}$ for 90 min according to Ahmad-Qasem et al. [23], ground to a size of $0.1 \mathrm{~mm}$ and stored at $-20{ }^{\circ} \mathrm{C}$ until further analysis. Water extracts were prepared according to Goldsmith et al. [24] while 50\% methanol and 50\% ethanol extracts were prepared according to Sahin et al. [19] (Figure 2). Extracts were concentrated (their volume reduced) using a rotary evaporator, freeze dried and then stored at $-20{ }^{\circ} \mathrm{C}$ until further analysis.

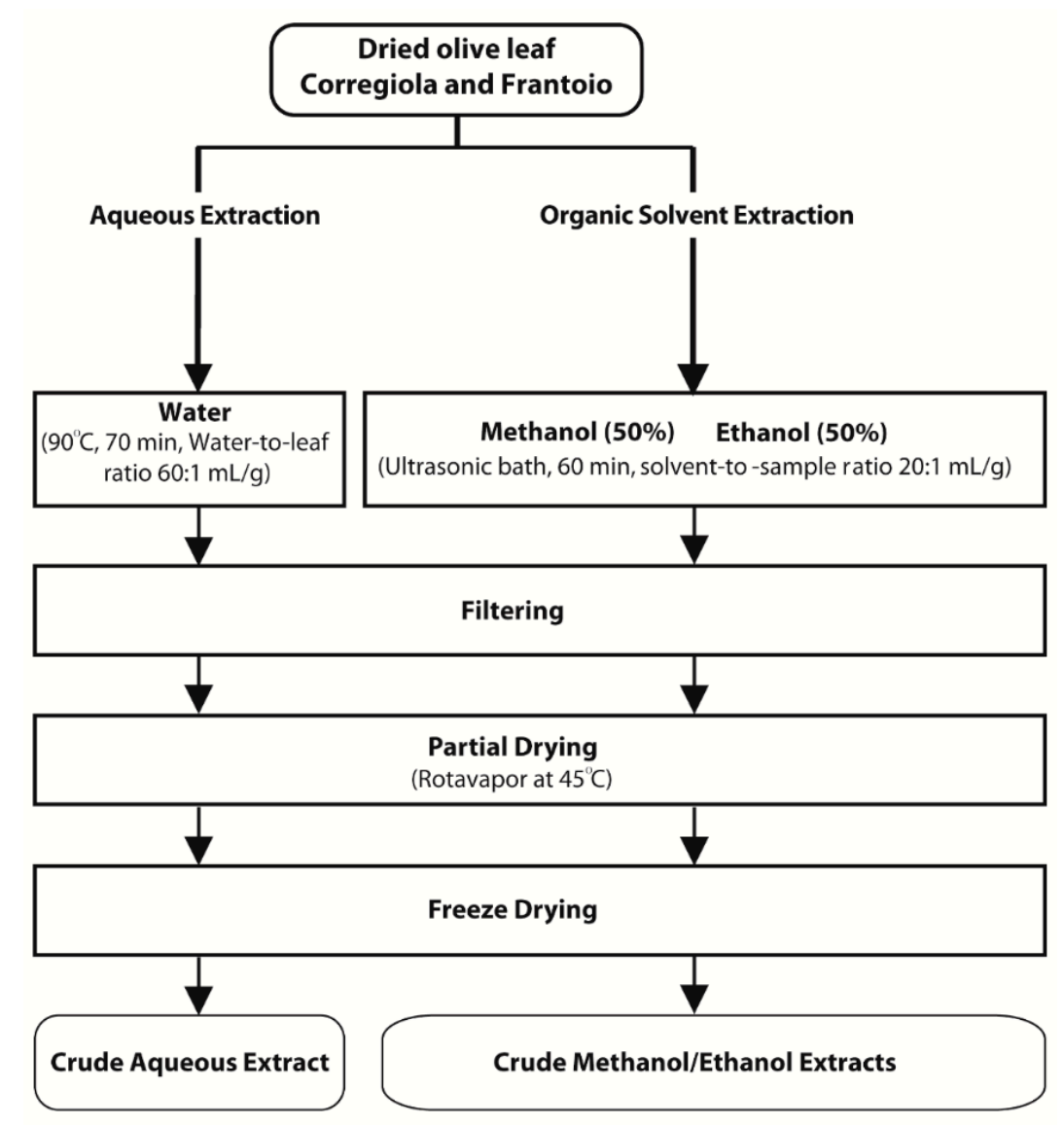

Figure 2. Methods for the preparation of olive leaf extracts. 


\subsection{Total Phenolic Compounds}

The total phenolic compounds (TPC) were determined according to Thaipong et al. [25]. Briefly, diluted samples $(300 \mu \mathrm{L})$ were added to Folin Ciocalteu's reagent $(300 \mu \mathrm{L})$ and left to equilibrate for 2 min before adding $2.4 \mathrm{~mL}$ of $5 \%$ sodium carbonate solution and incubated in the dark for $1 \mathrm{~h}$. Absorbance was then read at $760 \mathrm{~nm}$ using a UV spectrophotometer (Varian, Melbourne, VIC, Australia). Gallic acid was used as the standard and results were expressed as mg of gallic acid equivalents per $\mathrm{g}$ of sample dry weight (mg GAE/g).

\subsection{HPLC}

The olive leaf extracts were re-dissolved at $10 \mathrm{mg} / \mathrm{mL}$ and analysed using high performance liquid chromatography (HPLC) according to Goldsmith et al. [26] with some minor modifications. A Shimadzu HPLC system was used (Shimadzu Australia, Rydalmere, NSW Australia) with a $250 \times 4.6 \mathrm{~mm}$ Synergi $4 \mu \mathrm{m}$ Fusion-RP 80A reversed-phase column (Phenomenex Australia Pty. Ltd., Lane Cove, NSW Australia) with UV detection at $254 \mathrm{~nm}$. The column was maintained at $30{ }^{\circ} \mathrm{C}$, flow rate $1 \mathrm{~mL} / \mathrm{min}$ and the three solvents used for the mobile phase were: solvent $\mathrm{A}-1 \%$ acetonitrile in $0.2 \% \mathrm{H}_{3} \mathrm{PO}_{4}(v / v)$; solvent $\mathrm{B}-100 \%$ methanol; and solvent $\mathrm{C}-100 \%$ acetonitrile. A gradient elution schedule was used. The initial solvent system at the time of injection was $96 \%$ A, $2 \%$ B and $2 \% \mathrm{C}$. The eluting solvent was then changed, in a linear gradient manner, to $40 \% \mathrm{~A}, 30 \% \mathrm{~B}$ and $30 \% \mathrm{C}$ by $20 \mathrm{~min}$ and held there for $20 \mathrm{~min}$. From $40-42 \mathrm{~min}$, the solvent was then returned to $96 \% \mathrm{~A}, 2 \% \mathrm{~B}$ and $2 \% \mathrm{C}$ and maintained there for $10 \mathrm{~min}$ to re-equilibrate the column with the initial solvent system before the next injection. Gallic acid was used as an internal standard.

\subsection{Determination and Quantification of Oleuropein}

The HPLC peak corresponding to oleuropein was identified using an internal standard. The quantity of oleuropein in the extracts was determined using a standard curve of oleuropein prepared in methanol, which was linear between 0.05 and $0.925 \mathrm{mM}$, with the results expressed as mmol oleuropein per g dry weight $(\mathrm{mmol} / \mathrm{g})$.

\subsection{Flavonoids}

Total flavonoids were determined according to Vuong et al. [27]. Briefly, powdered extracts were redissolved at a concentration of $1 \mathrm{mg} / \mathrm{mL}$ in their respective solvents and $0.5 \mathrm{~mL}$ was added to $0.15 \mathrm{~mL}$ of $5 \%$ sodium nitrite, incubated for $6 \mathrm{~min}$ before adding $0.15 \mathrm{~mL}$ of $10 \%$ aluminium chloride and incubating for an additional $6 \mathrm{~min}$. Finally, $2 \mathrm{~mL}$ of sodium hydroxide was then added before incubating for a further $15 \mathrm{~min}$. Absorbance was then read at $510 \mathrm{~nm}$ using a UV spectrophotometer (Varian, Melbourne, VIC, Australia). Rutin was used as a standard and results were expressed as mg of rutin equivalents per $\mathrm{g}$ of sample dry weight (mg RE/g).

\subsection{Assessment of Antioxidant Capacity}

Three assays were employed to assess the antioxidant activity of the olive leaf extracts: 


\subsubsection{FRAP}

For the ferric reducing antioxidant power (FRAP) assay, the extract was diluted and then the ferric ion reducing capacity was determined according to Thaipong et al. [25]. Stock solutions were: (1) $300 \mathrm{mM}$ acetate buffer $\mathrm{pH}$, (2) $10 \mathrm{mM}$ TPTZ solution in $40 \mathrm{mM} \mathrm{HCl}$, (3) $20 \mathrm{mM} \mathrm{FeCl}_{3}$ solution. The fresh working solution was prepared by mixing $25 \mathrm{~mL}$ acetate buffer, $2.5 \mathrm{~mL}$ TPTZ solution and $2.5 \mathrm{~mL} \mathrm{FeCl} 3$ and then warming to $37^{\circ} \mathrm{C}$. Olive leaf extracts, trolox standards and blank $(150 \mu \mathrm{L})$ were then added to $2.85 \mathrm{~mL}$ of the working FRAP solution and left to incubate in the dark at $37^{\circ} \mathrm{C}$ for $30 \mathrm{~min}$. Absorbance was read at $593 \mathrm{~nm}$. Results were expressed as mg trolox equivalents per g of sample dry weight (mg TE/g).

\subsubsection{CUPRAC}

For the cupric reducing antioxidant capacity (CUPRAC) assay, the extracts were diluted and their cupric ion reducing capacity was determined as described by Apak et al. [28]. The stock solutions were: (1) $10 \mathrm{mM} \mathrm{CuCl}_{2}$ solution, (2) ammonium acetate buffer at $\mathrm{pH} 7.0$, (3) $7.5 \mathrm{mM}$ neocuproine (Nc) solution in $95 \%$ ethanol. A working solution of the three reagents $(1: 1: 1 \mathrm{v} / \mathrm{v})$ was prepared, $3 \mathrm{~mL}$ of which was added to $1.1 \mathrm{~mL}$ of the diluted extracts, trolox standards and blanks and left to react in the dark for $1 \mathrm{~h}$. Absorbance was read at $450 \mathrm{~nm}$. Results were expressed as $\mathrm{mg}$ of trolox equivalents per $\mathrm{g}$ of sample dry weight (mg TE/g).

\subsubsection{DPPH}

The free radical scavenging activity of the extracts was analyzed using the DPPH (1,1-diphenyl-2picrylhydrazyl) assay as described by Vuong et al. [29]. Briefly, the appropriately diluted samples, trolox standards and blank $(150 \mu \mathrm{L})$ were added to $2.85 \mathrm{~mL}$ of DPPH working solution (made to an absorbance of $1.1 \pm 0.01$ at $520 \mathrm{~nm}$ ) and left to react in the dark at room temperature for $3 \mathrm{~h}$. The results were expressed as $\%$ inhibition.

\subsection{Effect of Olive Leaf Extracts on Pancreas Cells}

\subsubsection{Pancreas Cell Culture}

Human pancreatic cancer (Mia-PaCa2) cells were cultured at $37{ }^{\circ} \mathrm{C}$ under $5 \% \mathrm{CO}_{2}$. Dulbecco's Modified Eagle's Medium (DMEM), supplemented with 10\% fetal bovine serum (FBS), 2.5\% horse serum and L-glutamine $(100 \mu \mathrm{g} / \mathrm{mL})$, was used.

\subsubsection{Assessment of Cell Growth Inhibition of Olive Leaf Extracts}

Cell growth inhibition was determined using the Dojindo Cell Counting Kit-8 (CCK-8: Dojindo Molecular Technologies Inc., Rockville, MD, USA). Cells were seeded into a 96 well plate at $5 \times 10^{3}$ cells per well and allowed to adhere for $24 \mathrm{~h}$. The cells were then treated with $50-200 \mu \mathrm{g} / \mathrm{mL}$ of crude olive leaf extracts, positive control gemcitabine $\left(\mathrm{IC}_{50}=50 \mathrm{nM}\right)$ or vehicle control. The concentration $50-200 \mu \mathrm{g} / \mathrm{mL}$ was chosen in order to show the range in which the extracts had activity on the cells. This was based on previously published data on the anti-proliferative activity of olive leaf extracts for breast cancer [30]. After $96 \mathrm{~h}, 10 \mu \mathrm{L}$ of CCK-8 solution was added before incubating at $37^{\circ} \mathrm{C}$ for $120 \mathrm{~min}$. 
The absorbance was measured at $450 \mathrm{~nm}$ and cell growth inhibition was determined as a percentage of control. All experiments were performed in triplicate.

\subsection{Statistical Analysis}

The one-way ANOVA and the LSD post-hoc test were used to assess mean differences in TPC levels, antioxidant capacity and cell viability between extracts using the JMP statistical software (Version 11). Data are represented as means \pm standard deviations for triplicate experiments. Differences between the means were taken to be statistically significant at $p<0.05$.

\section{Conclusions}

The development of novel extraction techniques to obtain bioactive compounds from biomass is gaining the interest of researchers as well as industry. The current study compared the phytochemical properties of six olive leaf extracts obtained from three different optimised extraction protocols: a "green" extraction method using water as a solvent, a 50\% methanol extraction method and a 50\% ethanol extraction protocol with the latter two also being ultrasound-assisted extraction techniques. While the TPC and antioxidant capacity of the extracts did not change depending on the extraction conditions, it is important to note that the levels of specific compounds did slightly vary and that there was a suggestion that the water extract of the Corregiola variety had the highest cytotoxicity of the leaf extracts against the MiaPaCa-2 pancreatic cancer cells. Although, the specific compounds causing cytotoxicity were not identified, it can be concluded that olive leaf extracts are a good source of phenolic compounds, including oleuropein. Furthermore, the olive leaf extracts at 100 and $200 \mu \mathrm{g} / \mathrm{mL}$ were found to significantly decrease the growth of the pancreatic cancer cells compared to the standard chemotherapeutic agent gemcitabine at its $\mathrm{IC}_{50}$.

This study is the first to show the anti-pancreatic cancer activity of olive leaf extracts and provides a foundation for further study of the activity of olive leaf compounds in pancreatic cancer. Moreover, this study shows the effectiveness and justifies the use of an environmentally friendly or "green" extraction method, which uses water, to extract bioactive compounds from olive leaves, including oleuropein and other phenolic compounds. This method could be easily scaled up and therefore shows great potential to benefit the olive oil production industry.

This is a preliminary study which aimed to assess the effectiveness of water as an extraction solvent for phenolic compounds from olive leaves and investigate olive leaf extracts as anti-pancreatic cancer agents. Limitations of this study include it being limited to one pancreatic cancer cell line and that the molecular mechanisms underlying activity were not investigated. Moreover, the individual compounds responsible for the anti-pancreatic cancer activity have not yet been identified. Nevertheless, this study provides a platform for further work to delineate the phenolic compound profile of olive leaf extracts as well as assess the molecular mechanisms involved in the anti-cancer activity of olive leaf extracts in pancreatic cancer cells. 


\section{Acknowledgments}

The authors would like to thank Christine and Jo Ashcroft of Houndsfield Estate for supplying the olive leaves. We acknowledge the following funding support: Ramaciotti Foundation (ES2012/0104); The University of Newcastle, and the Hunter Cancer Research Alliance (HCRA).

\section{Author Contributions}

Chloe D. Goldsmith participated in the experimental design and completion, as well as interpretation, manuscript design and preparation. Quan V. Vuong, Elham Sadeqzadeh, Costas E. Stathopoulos and Christopher J. Scarlett participated in the experimental design and data interpretation. Christopher J. Scarlett and Paul D. Roach participated in manuscript design and preparation. All authors read and approved the final manuscript.

\section{Conflicts of Interest}

The authors declare no conflict of interest.

\section{References}

1. Tsatsanis, C.; Androulidaki, A.; Venihaki, M.; Margioris, A.N. Signalling networks regulating cyclooxygenase-2. Int. J. Biochem. Cell Biol. 2006, 38, 1654-1661.

2. Sebolt-Leopold, J.S.; Herrera, R. Targeting the mitogen-activated protein kinase cascade to treat cancer. Nat. Rev. Cancer 2004, 4, 937-947.

3. Covas, M.I. Olive oil and the cardiovascular system. Pharmacol. Res. 2007, 55, 175-186.

4. De la Puerta, R.; Ruiz Gutierrez, V.; Hoult, J.R. Inhibition of leukocyte 5-lipoxygenase by phenolics from virgin olive oil. Biochem. Pharmacol. 1999, 57, 445-449.

5. Bisignano, G.; Tomaino, A.; lo Cascio, R.; Crisafi, G.; Uccella, N.; Saija, A. On the in-vitro antimicrobial activity of oleuropein and hydroxytyrosol. J. Pharm. Pharmacol. 1999, 51, 971-974.

6. Menendez, J.A.; Vazquez-Martin, A.; Colomer, R.; Brunet, J.; Carrasco-Pancorbo, A.; Garcia-Villalba, R.; Fernandez-Gutierrez, A.; Segura-Carretero, A. Olive oil's bitter principle reverses acquired autoresistance to trastuzumab (herceptin) in her2-overexpressing breast cancer cells. BMC Cancer 2007, 7, doi:10.1186/1471-2407-7-80.

7. Hassan, Z.K.; Elamin, M.H.; Omer, S.A.; Daghestani, M.H.; Al-Olayan, E.S.; Elobeid, M.A.; Virk, P. Oleuropein induces apoptosis via the p53 pathway in breast cancer cells. Asian Pac. J. Cancer Prev. 2013, 14, 6739-6742.

8. Hamdi, H.K.; Castellon, R. Oleuropein, a non-toxic olive iridoid, is an anti-tumor agent and cytoskeleton disruptor. Biochem. Biophys. Res. Commun. 2005, 334, 769-778.

9. Chimento, A.; Casaburi, I.; Rosano, C.; Avena, P.; De Luca, A.; Campana, C.; Martire, E.; Santolla, M.F.; Maggiolini, M.; Pezzi, V.; et al. Oleuropein and hydroxytyrosol activate gper/gpr30dependent pathways leading to apoptosis of er-negative skbr3 breast cancer cells. Mol. Nutr. Food Res. 2013, 58, 478-479. 
10. Carrera-González, M.P.; Ramírez-Expósito, M.J.; Mayas, M.D.; Martínez-Martos, J.M. Protective role of oleuropein and its metabolite hydroxytyrosol on cancer. Trends Food Sci. Technol. 2013, 31, 92-99.

11. Cardeno, A.; Sanchez-Hidalgo, M.; Rosillo, M.A.; Alarcon de la Lastra, C. Oleuropein, a secoiridoid derived from olive tree, inhibits the proliferation of human colorectal cancer cell through downregulation of hif-1alpha. Nutr. Cancer 2013, 65, 147-156.

12. Scarlett, C.J.; Smith, R.C.; Saxby, A.; Nielsen, A.; Samra, J.S.; Wilson, S.R.; Baxter, R.C. Proteomic classification of pancreatic adenocarcinoma tissue using protein chip technology. Gastroenterology 2006, 130, 1670-1678.

13. Chang, D.K.; Merrett, N.D.; Biankin, A.V.; Network, N.S.W.P.C. Improving outcomes for operable pancreatic cancer: Is access to safer surgery the problem? J. Gastroenterol. Hepatol. 2008, 23, 1036-1045.

14. Vuong, Q.V.; Scarlett, C.J.; Roach, P.D. Green tea and pancreatic cancer chemoprevention. In Green Tea: Varieties, Production and Health Benefits; Wu, W., Ed; Nova Science Publishers, Inc.: New York, NY, USA, 2012; Volume 1, pp. 77-93.

15. Siegel, R.; Naishadham, D.; Jemal, A. Cancer statistics, 2012. Cancer J Clin. 2012, 62, 10-29.

16. Biankin, A.V.; Waddell, N.; Kassahn, K.S.; Gingras, M.C.; Muthuswamy, L.B.; Johns, A.L.; Miller, D.K.; Wilson, P.J.; Patch, A.M.; Wu, J.; et al. Pancreatic cancer genomes reveal aberrations in axon guidance pathway genes. Nature 2012, 491, 399-405.

17. Xynos, N.; Papaefstathiou, G.; Gikas, E.; Argyropoulou, A.; Aligiannis, N.; Skaltsounis, A.L. Design optimization study of the extraction of olive leaves performed with pressurized liquid extraction using response surface methodology. Sep. Purif. Technol. 2014, 122, 323-330.

18. Taamalli, A.; Arraez-Roman, D.; Ibanez, E.; Zarrouk, M.; Segura-Carretero, A.; Fernandez-Gutierrez, A. Optimization of microwave-assisted extraction for the characterization of olive leaf phenolic compounds by using hplc-esi-tof-ms/it-ms(2). J. Agric. Food Chem. 2012, 60, 791-798.

19. Şahin, S.; Şaml1, R. Optimization of olive leaf extract obtained by ultrasound-assisted extraction with response surface methodology. Ultrason. Sonochem. 2013, 20, 595-602.

20. Seabra, R.M.; Vinha, A.F.; Ferreres, F.; Silva, B.M.; Valentao, P.; Goncalves, A.; Pereira, J.A.; Oliveira, M.B.; Andrade, P.B. Phenolic profiles of portuguese olive fruits (Olea europaea L.): Influences of cultivar and geographical origin. Food Chem. 2005, 89, 561-568.

21. Tan, S.P.; Parks, S.E.; Stathopoulos, C.E.; Roach, P.D. Extraction of flavanoids form bitter melon. Food Nutr. Sci. 2014, 5, 458-465.

22. Han, J.; Talorete, T.P.; Yamada, P.; Isoda, H. Anti-proliferative and apoptotic effects of oleuropein and hydroxytyrosol on human breast cancer mcf-7 cells. Cytotechnology 2009, 59, 45-53.

23. Ahmad-Qasem, M.H.; Barrajón-Catalán, E.; Micol, V.; Mulet, A.; García-Pérez, J.V. Influence of freezing and dehydration of olive leaves (var. Serrana) on extract composition and antioxidant potential. Food Res. Int. 2013, 50, 189-196.

24. Goldsmith, C.; Vuong, Q.; Stathopoulos, C.; Roach, P.; Scarlett, C. Optimization of the aqueous extraction of phenolic compounds from olive leaves. Antioxidants 2014, 3, 700-712.

25. Thaipong, K.; Boonprakob, U.; Crosby, K.; Cisneros-Zevallos, L.; Hawkins Byrne, D. Comparison of abts, dpph, frap, and orac assays for estimating antioxidant activity from guava fruit extracts. J. Food Compos. Anal. 2006, 19, 669-675. 
26. Goldsmith, C.D.; Stathopoulos, C.E.; Golding, J.B.; Roach, P.D. Fate of phenolic compounds during olive oil production with the traditional press method. Int. Food Res. J. 2014, 21, 101-109.

27. Vuong, Q.V.; Hirun, S.; Chuen, T.L.K.; Goldsmith, C.D.; Bowyer, M.C.; Chalmers, A.C.; Phillips, P.A.; Scarlett, C.J. Physicochemical composition, antioxidant and anti-proliferative capacity of a lilly pilly (syzygium paniculatum) extract. J. Herbal Med. 2014, 4, 134-140.

28. Apak, R.; Güçlü, K.; Özyürek, M.; Karademir, S.E. Novel total antioxidant capacity index for dietary polyphenols and vitamins $\mathrm{c}$ and e, using their cupric ion reducing capability in the presence of neocuproine: Cuprac method. J. Agric. Food. Chem. 2004, 52, 7970-7981.

29. Vuong, Q.V.; Hirun, S.; Roach, P.D.; Bowyer, M.C.; Phillips, P.A.; Scarlett, C.J. Effect of extraction conditions on total phenolic compounds and antioxidant activities of carica papaya leaf aqueous extracts. J. Herbal Med. 2013, 3, 104-111.

30. Elamin, M.H.; Daghestani, M.H.; Omer, S.A.; Elobeid, M.A.; Virk, P.; Al-Olayan, E.M.; Hassan, Z.K.; Mohammed, O.B.; Aboussekhra, A. Olive oil oleuropein has anti-breast cancer properties with higher efficiency on er-negative cells. Food Chem. Toxicol. 2013, 53, 310-316.

Sample Availability: Samples of the olive leaf extracts are available from the authors.

(C) 2015 by the authors; licensee MDPI, Basel, Switzerland. This article is an open access article distributed under the terms and conditions of the Creative Commons Attribution license (http://creativecommons.org/licenses/by/4.0/). 